Case report

\title{
Vertebral compression fracture during stereotactic body radiotherapy for spinal metastasis: A rare case of tracking failure ${ }^{\text {is }}$
}

\section{Fracture vertébrale en cours de radiothérapie stéréotaxique pour une métastase vertébrale : un cas rare d'échec de tracking}

\author{
S. Godin, A.-D. Durham, L. Schiappacasse, E.-M. Ozsahin*, F. Vilotte \\ Department of radiation oncology, centre hospitalier universitaire Vaudois, Bugnon 46, CH-1011 Lausanne, Switzerland
}

\section{A R T I C L E I N F O}

\section{Article history:}

Received 16 January 2020

Received in revised form 7 March 2020

Accepted 27 March 2020

\section{Keywords:}

SBRT

Tracking

Spinal metastasis

Cyberknife

Vertebral fracture

\begin{abstract}
A B S T R A C T
Spinal metastasis are a daily challenge in clinical practice. Stereotactic body radiotherapy (SBRT) allows delivery of definitive treatment with excellent long-term control rates. Its implementation needs dedicated devices and day-to-day image-guided radiotherapy (IGRT). The XSight ${ }^{\mathrm{TM}}$ spine tracking system, integrates with the CyberKnife ${ }^{\circledR}\left(\right.$ Accuray $\left.^{\mathrm{TM}}\right)$, provides a fiducial-free tracking system for spinal SBRT. We report a rare case of tracking failure during treatment due to the occurrence of a vertebral compression fracture (VCF).
\end{abstract}

() 2020 Société française de radiothérapie oncologique (SFRO). Published by Elsevier Masson SAS. All rights reserved.

\section{Mots clés :}

SBRT

" Tracking "

Métastase vertébrale

Cyberknife

Fracture vertébrale

\section{R É S U M É}

Les métastases vertébrales sont un défi quotidien en pratique clinique. La radiothérapie stéréotaxique (SBRT) permet de délivrer un traitement à visée ablative avec d'excellents taux de contrôle à long terme. Son implémentation nécessite des appareils dédiés et une imagerie de repositionnement (IGRT) quotidienne. Le " XSight ${ }^{\mathrm{TM}}$ spine tracking system », intégré avec le CyberKnife ${ }^{\circledR}$ (Accuray ${ }^{\mathrm{TM}}$ ), permet un " tracking » sans repère fiduciel pour la radiothérapie stéréotaxique vertébrale. Nous rapportons ici un cas rare d'échec de "tracking " en cours de traitement dû à l'apparition d'une fracture-tassement vertébrale.

(C) 2020 Société française de radiothérapie oncologique (SFRO). Publié par Elsevier Masson SAS. Tous droits réservés.

\section{Introduction}

Approximately one third of all cancer patients will develop bone metastasis of which approximately $70 \%$ will present metastasis involving the vertebral column [1-3]. Radiation therapy can be used to manage pain and to preserve or restore neurologic damages $[2,4,5]$.

\footnotetext{
A case of fracture-related tracking failure during spinal SBRT, S. Godin.

* Corresponding author.

E-mail address: Esat-Mahmut.Ozsahin@chuv.ch (E.-M. Ozsahin).
}

As cancer patients experience longer survival through improved systemic treatments and as there is a place for curative intent in oligometastic or oligoprogressive diseases, the aim of treatment of spinal metastasis for these patients is also to achieve tumor control $[2,3,6,7]$.

In this context, stereotactic body radiotherapy (SBRT) allows high doses and therefore increased tumor control while limiting the dose to the organs at risk (i.e., spinal cord) through a strong dose gradient and hypofractionation [1,3-6,8,9].

It requires dedicated radiotherapy systems, immobilization devices, and adapted image-guided radiotherapy (IGRT) $[1,10]$. Among the devices for performing spinal SBRT with these characteristics, the Cyberknife ${ }^{\circledR}$ 's Xsight ${ }^{\mathrm{TM}}$ Spine Tracking system (Accu- 


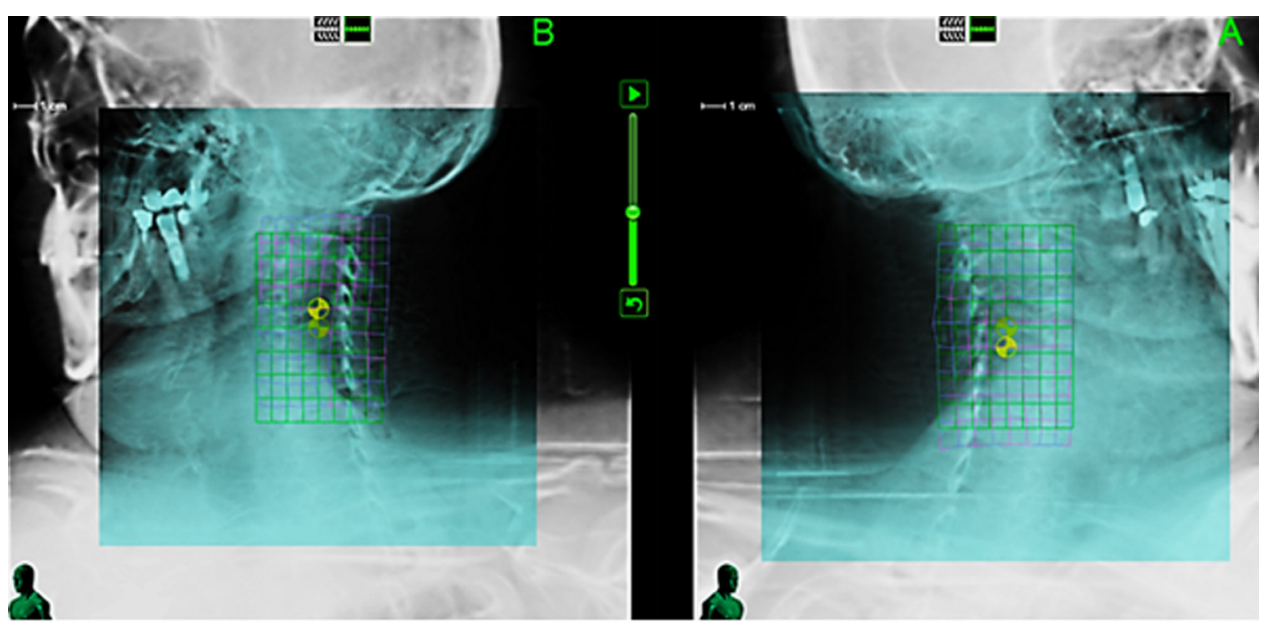

Fig. 1. XSight spine tracking system, showing misalignment between the orthogonal digitally reconstructed radiography (DRR) and the image-of-the-day grids.

ray, Sunnyvale, California) allows fiducial-free (non-invasive), safe and effective spine tracking [4-6,8,9,11].

We here expose an interesting case of tracking failure of the Cyberknife ${ }^{\circledR}$ during a vertebral SBRT.

\section{Case report}

We report the case of a 65-year-old man treated for an initial stage IVA lung adenocarcinoma, with a single brain metastasis at diagnosis. Treatment consisted of brain radiosurgery, neoadjuvant chemotherapy (cisplatine-pemetrexed) followed by surgery and adjuvant thoracic radiochemotherapy.

Three months after treatment completion, a single lytic spinal metastasis on vertebra C 3 was found on follow-up exams, with corpus and left pedicle invasion. No collapse was highlighted, and pain was efficiently managed by medication. After tumor board evaluation, this lesion was considered stable with a spinal instability neoplastic score (SINS) of 8, and an SBRT treatment by Cyberknife ${ }^{\circledR}$ was decided [12].

Planification consisted of a millimetric scanographic acquisition with a 3-point thermoplastic mask, registered with a 3D spine magnetic resonance imaging (MRI) for volume delineation. Prescription was for a total dose of 30/35 Gy in 5 fractions with simultaneous integrated boost (SIB) on the gross tumor volume (GTV). Clinical target volume (CTV) was defined following international guidelines $[3,13,14]$. The maximal dose on a volume of $0.035 \mathrm{~cm}^{3}$ (Dmax) to the spinal cord was $20.32 \mathrm{~Gy}$, the V20 of the spinal cord was $0.06 \mathrm{~cm}^{3}$. Tracking was assured by the $\mathrm{XSight}^{\mathrm{TM}}$ spine tracking system, and each fraction was supposed to last 45 minutes.

The first fraction took place as planned, but due to severe neck pain in treatment position, pain medication was adjusted. The second fraction needed to be pushed back twice due to neck pain and the inability to correctly track the vertebra. Pain was initially attributed to a flare up effect and managed by pain medication adaptation. Tracking difficulties were imputed to projection of the mandible on the tracking grid, and the modification in spine curvature was imputed to pain (Fig. 1). Finally, on the third attempt, the second fraction was completed but recurrent tracking difficulties doubled the expected treatment time. The delivery of the third fraction was also very difficult because of pain and tracking difficulties. Due to these difficulties, these 3 fractions were delivered in 11 days, instead of 5 days as usually in our department.

These difficulties led us to replan the treatment. On the second planning computer tomography (CT) scan, a C3 compression fracture was found, with a near 5-mm corpus height loss compared to initial imagery (Fig. 2). Revision of daily orthogonal images with a radiologist showed that the spinal fracture occurred probably
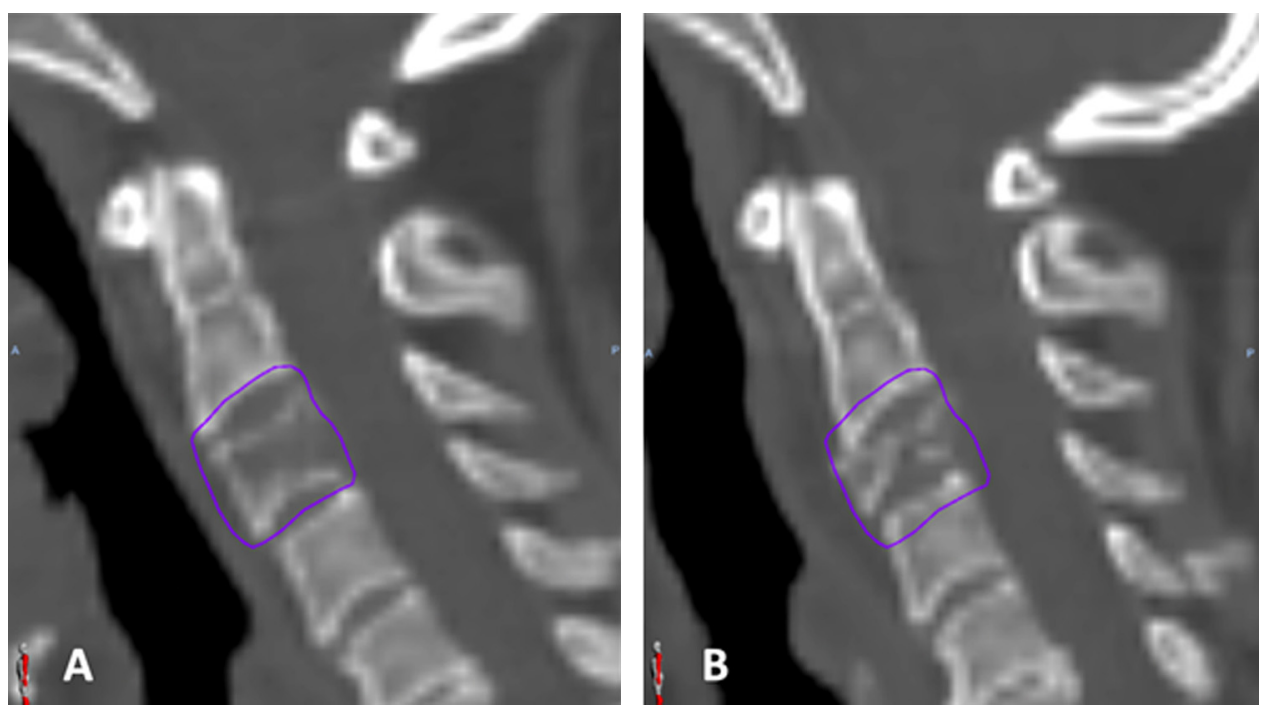

Fig. 2. Planning CT-scan before (A) and after (B) C3 vertebral compression fracture. 
between the first and second fractions, explaining the increased pain and tracking difficulties described above. The recalculated dose on the second CT-scan (on which the C3 compression fracture was diagnosed) showed a defavorable situation with an increased dose to the spinal cord compared to the initial plan, with an estimated Dmax of $27.63 \mathrm{~Gy}$, a V20 and a V22.5 of $0.53 \mathrm{~cm}^{3}$ and $0.27 \mathrm{~cm}^{3}$ respectively, for the complete plan. Moreover, further treatment with the initial plan was not possible because of the tracking difficulties and, more importantly, stabilization of the C3 vertebra was necessary, fortunately still without neurologic symptoms.

After a new tumor board discussion, a kyphoplasty was performed, 3 weeks after the CT-scan on which the C3 compression fracture was diagnosed, with a good antalgic effect, and a new SBRT treatment was decided to complete the treatment. Two complementary fractions were delivered 16 days after the kyphoplasty but, in view of the problems encountered during the first phase of the treatment (vertebral compression fracture, tracking difficulties, uncertainties concerning the timing of the compression fracture and the spinal cord dose), we decided to reduce the fraction dose to 5/5.85 Gy to prevent the risk of neurologic complications. The composite dosimetry of the 2 SBRT treatments ( 3 fractions of the first plan and 2 of this new plan post kyphoplasty) showed a Dmax of $22.32 \mathrm{~Gy}$, a V20 and a V22.5 of $0.11 \mathrm{~cm}^{3}$ and $0.029 \mathrm{~cm}^{3}$ respectively. No difficulty was encountered for this new treatment.

The patient unfortunately died 3 months later due to rapid progression of the disease, particularly in the form of pleural carcinomatosis.

\section{Discussion}

To our knowledge, there is no case described in the literature of vertebral tracking failure by Cyberknife ${ }^{\circledR}$ during a spine SBRT due to anatomical modification during treatment. We wanted to expose this example of tracking failure and also to review the different pitfalls in the management of vertebral metastasis by SBRT, especially using the Xsight ${ }^{\mathrm{TM}}$ spine tracking system.

Spinal stability is a key factor in the decision to treat vertebral metastasis. Vertebral instability in the context of metastasis is not clearly defined, and the Spine Oncology Study Group (SOSG) proposed the SINS score to provide a simple and objective system for assessing relative stability of a metastatic vertebra, which thus allows to recognize, in the absence of neurological signs, unstable or potentially unstable situations. The SINS scores lesions on a scale from 0-18 using six variables - pain, location, bone lesion quality (lytic/blastic), alignment, vertebral body collapse, and posterolateral element involvement. Lesions are then described as stable (0-6), potentially unstable (7-12), or unstable (13-18) [12]. This score shows a great intra- and inter-observer reliability and is simple to use for any physician, with increased reliability with training [15]. Nevertheless, this score has never been evaluated prospectively, and is an expert consensus. Moreover, optimal management of the intermediate category is not clearly defined. The attitude of spinal surgeons in this intermediate category was analyzed retrospectively to detect a possible cut-off from which an intervention is performed, and it was noted that only $11 \%$ of SINS $<10$ benefited from surgical intervention against almost $80 \%$ of SINS $>10$. The predominant SINS factors leading to an intervention are a lytic bone lesion, the loss of vertebral body height, and the involvement of the posterolateral elements of the vertebra [10]. In our situation, the SINS calculated at our tumor board was 8 (potentially unstable), without loss of height of the vertebral body. Nevertheless, it is possible that this score was initially underestimated, in particular by underestimating the patient's pain (the most subjective variable of the SINS [16]), and the patient did not benefit from a consultation with a surgeon, as recommended for patients in the intermediate category [12].

After standard external beam radiotherapy (EBRT), the risk of vertebral compression fracture (VCF) is around 3\% with a low rate of local control whereas the risk after SBRT can increase to almost $40 \%$ but with local control rates $>80 \%$ [17]. The risk of VCF after a single-fraction SBRT is high with an important influence of the dose per fraction. Indeed, the VCF risk is $39 \%$ for a dose $>24 \mathrm{~Gy}, 19 \%$ for $20-23 \mathrm{~Gy}$, and $10 \%$ for < $19 \mathrm{~Gy}$. With fractionated SBRT, the risk of fracture is $<5 \%$ (close to the EBRT risk), while keeping a good local control of $>80 \%$ [18]. Single-dose spinal SBRT should therefore be used with caution, given the high risk of complications. In addition to the dose per fraction, other predictor factors of VCF after SBRT have been identified, including some criteria used in the SINS: a lytic tumor, pre-existing vertebral fracture, and column deformity [19]. Moreover, other characteristics were identified as predictors in some studies only, such as some histologies (lung and hepatocellular carcinoma), age $>55$ years, location from thoracic 10 vertebra to the sacrum, major invasion of the vertebral body by the lesion (especially if lytic), and a high pain score [16,20]. Mean time between spinal SBRT and VCF is about 3 months, and 65\% of VCF occur within the first 4 months, even though it can happen more than 1 year after [1]. In our case, we chose a fractionated SBRT with 5 fractions of 6/7 Gy per fraction, and identified that the VCF occurred probably between the first and the second fractions. So, it seems improbable that only one fraction of SBRT led to this VCF.

The Xsight ${ }^{\mathrm{TM}}$ spine tracking system of the CyberKnife ${ }^{\circledR}$ uses $\mathrm{X}$-ray image-guided targeting, and a robotically manipulated lightweight linear accelerator to track the metastatic vertebra. The X-ray targeting system repeatedly (typically every 30-60 seconds) acquires high-resolution digital images onto paired orthogonal amorphous silica detectors during treatment. These images are registered to digitally reconstructed radiographs (DRR) generated from the planning CT-scan. During the SBRT planning, a region of interest (ROI) is defined on these DRRs, usually around the target. Within this ROI, a grid is positioned. Differences in translational and rotational axes between the X-ray image and the DRR based on the nodes of the grid surrounding bony structures around the target are measured and used to maintain spatial precision. The process of image acquisition, processing, registration, and re-targeting is automatic, and quickly repeated during treatment $[5,11]$. In our situation, the location of the treated vertebra (C3) was misleading because the tracking difficulties were falsely attributed to the projection of the mandible, a mobile bone structure, which was in the tracking field, and which can therefore lead to difficulties for tracking, instead of searching for an anatomical change of C3. In addition, the orthogonal imaging performed for tracking is difficult to interpret clinically, and did not allow us to diagnose the vertebral fracture.

Since the case of our patient described above, our management of vertebral SBRT has changed. The SINS is calculated for all patients presented at our vertebral metastasis tumor board, in the presence of neurosurgeons and interventional radiologists. We systematically assess the indication of a stabilization before every SBRT, even with a low intermediate SINS. Moreover, we do a new radiological assessment much faster in case of symptom modifications or tracking difficulties during treatment.

In conclusion, the management of vertebral metastasis should be discussed in a multidisciplinary setting, and SINS should be calculated to avoid any complication by a possible combined approach between neurosurgery, interventional radiology, and radiotherapy. This method should be preferred especially in the context of treatment with curative intent where high doses per fraction are delivered. Moreover, in front of any clinical modification or any tracking difficulty with the XSight ${ }^{\mathrm{TM}}$ spine tracking system, one must not hesitate to redo planning diagnostic imaging in order to 
search for any evolution in the anatomy between planning CT and the treatment.

\section{Contribution of authors}

S. Godin: conceptualization, methodology, investigation and writing.

F. Vilotte: conceptualization, methodology, investigation, writing and supervision.

E-M. Ozsahin: supervision and validation.

L. Schiappacasse: supervision.

A-D. Durham: supervision.

\section{Disclosure of interest}

The authors declare that they have no competing interest.

\section{References}

[1] De Bari B, Alongi F, Mortellaro G, Mazzola R, Schiappacasse L, Guckenberger M. Spinal metastases: is stereotactic body radiation therapy supported by evidences? Crit Rev Oncol Hematol 2016;98:147-58.

[2] Faivre JC, Py JF, Vogin G, Martinage G, Salleron J, Royer P, et al. Radiothérapie conformationnelle des métastatses osseuses vertébrales. Cancer Radiother 2016;20:493-9.

[3] Pasquier D, Martinage G, Mirabel X, Lacornerie T, Makhloufi S, Faivre JC, et al. Radiothérapie stéréotaxique des métastases osseuses vertébrales. Cancer Radiother 2016;20:500-7.

[4] Gerszten PC, Ozhasoglu C, Burton SA, Vogel WJ, Atkins BA, Kalnicki S, et al. CyberKnife frameless stereotactic radiosurgery for spinal lesions: clinical experience in 125 cases. Neurosurgery 2004;55:89-98.

[5] Gibbs IC, Kamnerdsupaphon P, Ryu MR, Dodd R, Kiernan M, Chang SD, et al. Image-guided robotic radiosurgery for spinal metastases. Radiother Oncol 2007;82:185-90

[6] Thariat J, Leysalle A, Vignot S, Marcy PY, Lacout A, Bera G, et al. Traitement local ablatif de la maladie oligométastatique osseuse (hors chirurgie). Cancer Radiother 2012:16:330-8.

[7] Palma D, Olson R, Harrow S, Gaede S, Louie A, Haasbeek C, et al. Stereotactic ablative radiotherapy versus standard of care palliative treatment in patients with oligometastatic cancers (SABR-COMET): a randomised, phase 2, openlabel trial. Lancet 2019;393:2051-8.

[8] Ho AK, Fu D, Cotrutz C, Hancock SL, Chang SD, Gibbs IC, et al. A study of the accuracy of cyberknife spinal radiosurgery using skeletal structure tracking. Neurosurgery 2007;60:ONS147-56.

[9] Tsai JT, Lin JW, Chiu WT, Chu WC. Assessment of image-guided cyberKnife radiosurgery for metastatic spine tumors. J Neurooncol 2009;94:119-27.

[10] Pennington Z, Ahmed AK, Westbroek EM, Cottrill E, Lubelski D, Goodwin ML, et al. SINS Score and stability: evaluating the need for stabilization within the uncertain category. World Neurosurg 2019;127:e1034-47.

[11] Bondiau PY, Bénézery K, Beckendorf V, Peiffert D, Gérard JP, Mirabel X, et al. Radiothérapie stéréotaxique robotisée par cyberknife : aspects techniques et indications. Cancer Radiother 2007;11:338-44.

[12] Fisher CG, DiPaola CP, Ryken TC, Bilsky MH, Shaffrey CI, Berven SH, et al. A novel classification system for spinal instability in neoplastic disease: an evidencebased approach and expert consensus from the Spine Oncology Study Group. Spine 2010;35:E1221-9.

[13] Cox BW, Spratt DE, Lovelock M, Bilsky MH, Lis E, Ryu S, et al. International spine radiosurgery consortium consensus guidelines for target volume definition in spinal stereotactic radiosurgery. Int J Radiat Oncol 2012;83:e597-605.

[14] De Méric de Bellefon M, Vilotte F, Jumeau R, Saliou G, Bartolini B, Ruiz-Lopez $\mathrm{N}$, et al. Radiothérapie stéréotaxique vertébrale par cyberknife : résultats du centre hospitalier universitaire vaudois. Cancer Radiother 2018;22:703-41.

[15] Pennington Z, Ahmed AK, Cottrill E, Westbroek EM, Goodwin ML, Sciubba DM Intra- and interobserver reliability of the Spinal Instability Neoplastic Score system for instability in spine metastases: a systematic review and meta-analysis. Ann Transl Med 2019;7:218.

[16] Sahgal A, Atenafu EG, Chao S, Al-Omair A, Boehling N, Balagamwala, et al. Vertebral compression fracture after spine stereotactic body radiotherapy: a multi-institutional analysis with a focus on radiation dose and the Spinal Instability Neoplastic Score. J Clin Oncol 2013;31:3426-31.

[17] Huo M, Sahgal A, Pryor D, Redmond K, Lo S, Foote M. Stereotactic spine radiosurgery: review of safety and efficacy with respect to dose and fractionation. Surg Neurol Int 2017;8:30.

[18] Mehta N, Zavitsanos PJ, Moldovan K, Oyelese A, Fridley JS, Gokaslan Z, et al. Local failure and vertebral body fracture risk using multifraction stereotactic body radiation therapy for spine metastases. Adv Radiat Oncol 2018;3:245-51.

[19] Chang JH, Shin JH, Yamada YJ, Mesfin A, Fehlings MG, Rhines LD, et al. Stereotactic body radiotherapy for spinal metastases: what are the risks and how do we minimize them? Spine 2016;41:S238-45.

[20] Jawad MS, Fahim DK, Gerszten PC, Flickinger JC, Sahgal A, Grills IS, et al. Vertebral compression fractures after stereotactic body radiation therapy: a large, multi-institutional, multinational evaluation. J Neurosurg Spine 2016;24:928-36. 